\title{
Determination of the minimum wind speed leading to the galloping of conductors
}

\author{
Muratkali Zhamanbaev ${ }^{1}$, Diana Ilieva $^{2^{*}}$, Rakhimash Abitaeva ${ }^{3}$, Bulbul Ongar ${ }^{3}$ \\ ${ }^{1}$ Department of Power Engineering, Almaty Technological University, Tole bi Str., 100, Kazakhstan \\ ${ }^{2}$ University of Telecommunications and Post - Sofia, 1 Academician Stefan Mladenov Str., 1700 \\ Sofia, Bulgaria \\ ${ }^{3}$ Department of Power Engineering KazATC after named M.Tynyshpayev, Shevchenko Str., 97, \\ Kazakhstan
}

\begin{abstract}
The object of research in this paper is the split phase of overhead power lines. The study of the aeroelastic instability of the icy conductors of the split phase for a multi-span system has already been explored using the method of determining the Hurwitz stability criterion. In multi-span systems, where conductors are interconnected through a garland of insulators, the garlands themselves are involved in an oscillatory process. As a result of this, mutual influence of adjacent spans is observed - energy is transferred from one span to another. The paper investigates the aeroelastic instability of the icy conductors of the split phase in the anchor span, which is characterized by two intrinsic features: the attachment point of conductors on the supports is fixed and mutual effects between adjacent spans are not observed. The study of motion instability is carried out by the first approximation method, that is, on the basis of linearization of the nonlinear equation at the equilibrium point and further investigation of the linearized equation in the vicinity of this point. The results of the study are based on the novelty of the carried out experiments - taking into account the peculiarities of the anchor span and the findings based on the analysis of empirical data.
\end{abstract}

\section{Introduction}

A lot of research and papers have been devoted to the study of galloping conductors [111]. For example, in [1] the research is devoted to assessing the maximum excursion of single conductors and bundled galloping of conductors.

Interesting contributions may also come from the comparison between analytical/numerical results and experimental data inferred from full-scale galloping observations [2], wind tunnel tests $[3,4]$ or on a high-voltage overhead test line [5]. Free torsional oscillation of a split conductor of an overhead transmission line is considered. The obtained calculation formulas are recommended for use in the design of new overhead transmission lines with split conductors and reconstruction of lines being already in operation [6]. Numerical approaches based on the curved cable-beam theory are considered

*Corresponding author: diana edubg@abv.bg 
promising for single cables [7]. Galloping refers to wind-induced, low-frequency largeamplitude oscillations that have been more frequently observed for a bundle conductor than for a single conductor [8]. The galloping instability analysis shows that the occurrence of negative aerodynamic damping strongly depends on the critical flow state. In all cases considered in [9], the critical Reynolds number effects are shown to include aerodynamic forces that could well be responsible for the whole range of translational galloping instabilities and the part range of torsional flutter and 3-DOF galloping instabilities for semi-elliptical cylinders.

The study of transverse galloping at low values of the Reynolds number allows the following observations to be made [10]: galloping for a square cylinder is observed only for Reynolds number larger than 140; and a sinusoidal quasi-steady model accurately reproduces amplitudes obtained from fluid-structure interaction simulations for moderately high values of the mass ratio.

\section{Determination of the critical speed of wind leading to aerodynamic instability of conductors}

Currently, a serious part of the analysis of the phenomena of "galloping" is determining the value of the minimum (critical) wind speed, leading to an unstable state of the icy conductor of power lines. There are few works regarding this issue [11-16], especially concerning the split-phase [14]. Below, a method for determining the critical velocity for the split-phase of the lines of the anchor section is proposed by the authors. In [17,18], a mathematical model of the galloping of conductors of a split-phase with two degrees of freedom is presented. Neglecting the generalized coordinates of torsional motion in this model, we obtain the equations of motion for galloping of conductors with one degree of freedom

$$
\ddot{a}(t)+k_{1} \dot{a}(t)+k_{2} \dot{a}^{3}(t)+\omega_{a}^{2} a(t)+k_{3} a^{2}(t)+k_{4} a^{3}(t)+k_{13}=0
$$

where the coefficients of the equation are calculated with the following expressions:

$$
\begin{gathered}
\ddot{a}(t)=\frac{d^{2} a(t)}{d t^{2}} ; \quad \dot{a}(t)=\frac{d a(t)}{d t} ; \quad k_{1}=\frac{\delta \cdot \omega_{a}}{\pi}-\frac{2 g \cdot \rho \cdot d_{S} \cdot\left(C_{D 0}+C_{L 0}\right) V}{\pi \cdot P_{W}} ; \\
k_{2}=\frac{4 g \cdot \rho \cdot d_{S}}{3 \pi \cdot P_{W} \cdot V} C_{L 1} ; \quad k_{3}=\frac{3 \pi \cdot g \cdot E \cdot F}{T \cdot l^{2}} ; \quad k_{4}=\frac{\pi^{2} \cdot g \cdot E \cdot F}{4 \cdot P_{W} \cdot l^{4}} \\
k_{13}=\frac{g \cdot \rho^{2} \cdot d_{S}^{2} \cdot C_{D 0}^{2} \cdot V^{4}}{2 \cdot P_{W}^{2}} ; \quad \omega_{a}=\frac{\pi}{l} \sqrt{\frac{g \cdot T}{P_{W}}\left(1+\frac{8 E \cdot F \cdot P_{W}^{2} \cdot l^{2}}{\pi^{4} \cdot T^{3}}\right) .}
\end{gathered}
$$

Here $a(t)$ is the generalized coordinate of linear displacements, m;

$l$ - span length, m;

$\mathrm{g}$ - acceleration of gravity force, $\mathrm{m} / \mathrm{s}^{2}$;

$\rho$ - the density of the air stream, daN $\cdot \mathrm{s}^{2} / \mathrm{m}^{4}$;

$\mathrm{d}_{\mathrm{S}}$ - the typical size of the cross section of the ice-covered conductor, $\mathrm{m}$;

$\delta$ - decrement of damping;

$\mathrm{V}-$ wind speed, $\mathrm{m} / \mathrm{s}$;

$P_{0}$ - weight per unit length of conductor, daN/m;

$P_{W}$ - weight per unit length of icy conductor, daN/m;

$T$ - conductor tension, daN; 
E - elastic modulus, daN $/ \mathrm{mm}^{2}$;

$F$ - conductor cross-sectional area, $\mathrm{mm}^{2}$;

$\mathrm{C}_{\mathrm{D} 0}$ - aerodynamic coefficient of force of frontal pressure;

$\mathrm{C}_{\mathrm{L} 0}$ and $\mathrm{C}_{\mathrm{L} 1}$ - aerodynamic lift factors;

$\omega_{\mathrm{a}}-$ frequency of free transverse vibration of the conductor, $\mathrm{rad} / \mathrm{s}$.

Introducing the notation $a(t)=y_{0}$ and $\dot{a}(t)=y_{1}$, we represent (1) in the normal form

$$
\left\{\begin{array}{c}
\dot{y}_{0}=y_{1} \\
\dot{y}_{1}=-k_{1} \cdot y_{1}-k_{2} \cdot y_{1}^{3}-\omega_{a}^{2} \cdot y_{0}-k_{3} \cdot y_{0}^{2}-k_{4} \cdot y_{0}^{3}-k_{13}
\end{array}\right.
$$

Equating the equations in the system (2) $\dot{y}_{0}(t)=0$ and $\dot{y}_{1}(t)=0$ we obtain an expression for the determination of the equilibrium position

$$
y_{0}^{3}+\frac{k_{3}}{k_{4}} y_{0}^{2}+\frac{\omega_{a}^{2}}{k_{4}} y_{0}+\frac{k_{13}}{k_{4}}=0 .
$$

The solution of equations (3) by the iterative method gives the following result

$$
y_{01} \approx-\frac{k_{13}}{\omega_{a}^{2}}
$$

where $\mathrm{y}_{01}$ - the result of the first approximation.

We linearize system (2) in a neighborhood of the equilibrium point 0.25 point $\left(y_{01}, 0\right)$

$$
\left\{\begin{array}{c}
\dot{y}_{0}=y_{1}, \\
\dot{y}_{1}=\left(\frac{2 k_{3} \cdot k_{13}}{\omega_{a}^{2}}-\omega_{a}^{2}\right) y_{0}-k_{1} \cdot y_{1} .
\end{array}\right.
$$

The characteristic equation of a linearized system (5) is:

$$
p^{2}+k_{1} \cdot p+\omega_{a}^{2}-\frac{2 k_{3} \cdot k_{13}}{\omega_{a}^{2}} \approx p^{2}+k_{1} \cdot p+\omega_{a}^{2}=0
$$

The characteristic equation (6) has complex conjugate roots

$$
p_{1,2}=-\frac{1}{2} k_{1} \pm j \omega_{a}
$$

The solution of the linearized equation, taking into account the initial conditions $y_{0}=a(0)=A_{0}$ and $y_{1}=\dot{a}(0)=0$ has the form

$$
a(t)=A_{0} e^{\frac{-k_{1}}{2} \cdot t}\left(\cos \omega_{a} t+\frac{k_{1}}{2 \omega_{a}} \sin \omega_{a} t\right),
$$

where

$$
k_{1}=\frac{\delta \cdot \omega_{a}-2 b_{3} \cdot\left(C_{D 0}+C_{L 0}\right) \cdot V}{\pi} .
$$

As follows from formula (8), under the condition $\mathrm{k}_{1}=0$, the split phase performs undamped periodic oscillations. Equating the coefficient $\mathrm{k}_{1}$ to zero, we find the minimum wind speed at which the split phase performs undamped oscillations with a constant 
amplitude $A_{0}$ and frequency $\omega_{a}$ (the value of coefficient $b_{3}$ is taken into account during the transformation)

$$
V_{K R}^{H}=\frac{P_{W} \cdot \delta \cdot \omega_{a}}{2 g \cdot \rho \cdot d_{S} \cdot\left(C_{D 0}+C_{L 0}\right)} .
$$

It follows from formula (9) that the lower critical speed is influenced by the damping decrement [20], the weight of the ice sediment, the frequency of natural transverse vibrations of the conductors (therefore, the characteristics of power lines), air density, geometric dimensions, and stationary aerodynamic coefficients of ice deposition. A similar study was carried out in [19], only with respect to a multi-span system, when the conductors are interconnected through garlands of insulators. In [19], processes for a multispan system are considered whereas this paper considers an anchor span. The novelty of the present work consists in experiments and conclusions related to various features of the anchor span. The analysis of experiments has shown that the value of the critical wind speed at which the galloping of conductors is excited does not depend on the method of attaching the conductor to the support (rigid attachment or through garlands of insulators that give some mobility). If in article [19] the calculation formula is obtained by applying Hurwitz stability criterion, the novelty in the present elaboration consists in researching the stability of nonlinear systems which has been conducted in the first approximation, i.e. based on the linearization of nonlinear equations at the equilibrium point and on the further study of the linearized equation in the neighbourhood of these points.

Therefore, the value of the lower critical speed is not affected by the way the conductor is fixed to the support, that is, rigid anchor fastening or movable - through the garlands of insulators.

\section{The modeling process}

The verification of the obtained results has been carried out by modeling of the initial nonlinear system (2) in the vicinity of the critical velocity (9). Transients are obtained using Mathcad and applying the Runge-Kutta method with a fixed step which is shown in Fig.1,2. The calculations have been performed for a split phase of 3 conductors AC-300/39.

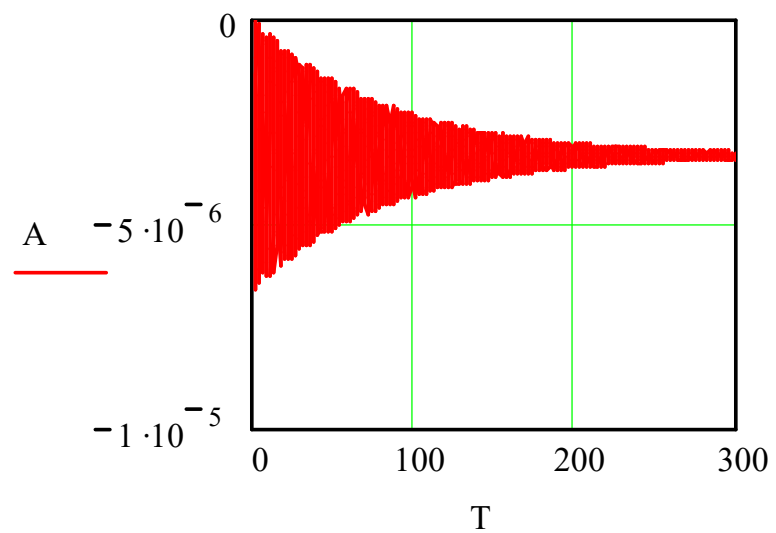

Fig. 1. Transient processes in $l=200 \mathrm{~m}$ and $10 \mathrm{daN} / \mathrm{mm}^{2}$ where $V=1 \mathrm{~m} / \mathrm{s}<V_{K R}$

In the figure - the ordinate: A, $\mathrm{m}$ - amplitude galloping of conductors; on the abscissa: $\mathrm{T}, \mathrm{s}$ - the current time. 
As follows from Fig.1, if the wind speed is less than the critical speed determined by the formula (9) $\left(V<V_{K R}\right)$, then the oscillation process (galloping of conductor) is not supported by the system and fades over time.

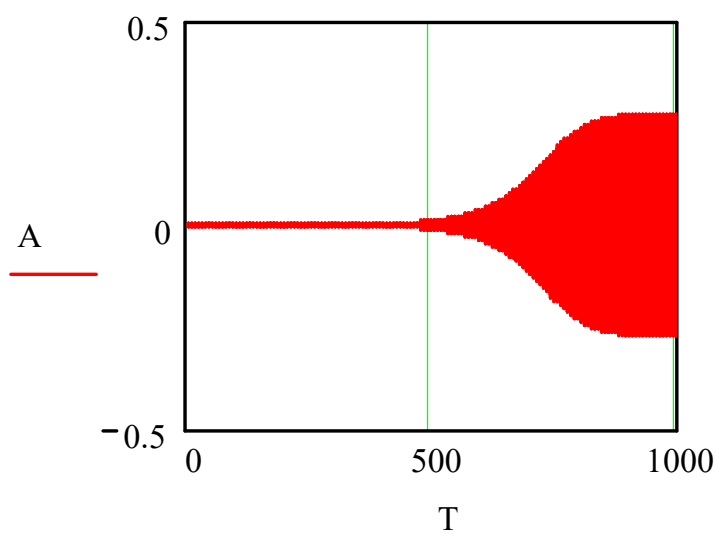

Fig. 2. Transient processes in $l=200 \mathrm{~m}$ and $10 \mathrm{daN} / \mathrm{mm}^{2}$ where $V=1,6 \mathrm{~m} / \mathrm{s}>V_{K R}$

If the wind speed is greater than the critical speed determined by the formula (9) $\left(V>V_{K R}\right)$, then the oscillation process is supported by the system and after the end of the transition process, a stable oscillation process with an amplitude of $0,25 \mathrm{~m}$ is observed (Fig.2). It should also be noted, that usually the frequency of the galloping coincides with the frequency of the free oscillation of the conductor.

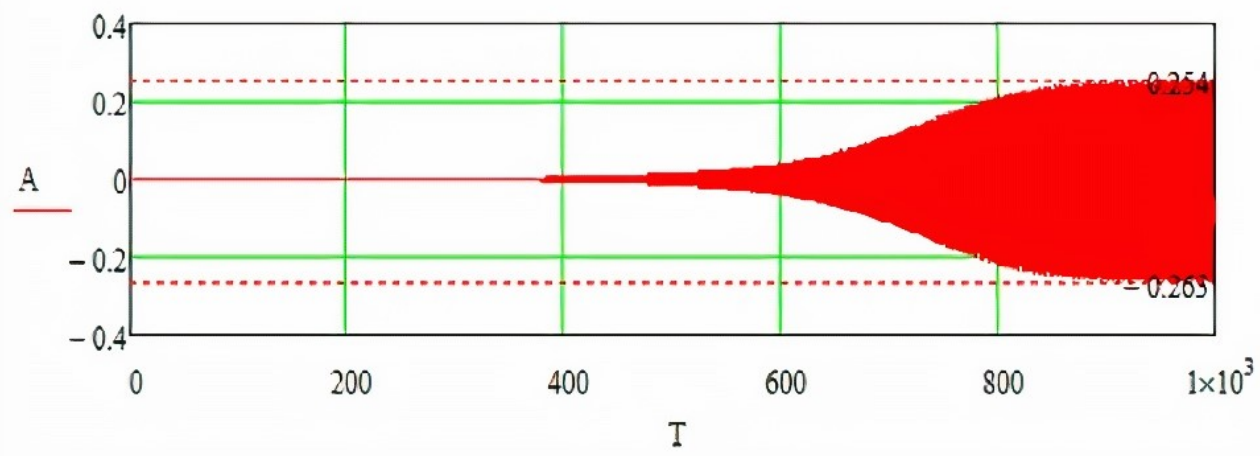

Fig. 3. Transient processes in $l=200 \mathrm{~m}$ and $10 \mathrm{daN} / \mathrm{mm}^{2}$ where $V=2,1 \mathrm{~m} / \mathrm{s}>V_{K R}$

Fig. 3 shows the simulation result for the wind speed $V=2,1 \mathrm{~m} / \mathrm{s}$ and for the obtained critical speed $V_{K R}=1,72 \mathrm{~m} / \mathrm{s}$. As can be seen from Fig.3, after the end of the transition process, the duration of which has been approximately $900 \mathrm{~s}$, there is a stable oscillatory process with amplitudes of $0,254 \mathrm{~m}$ and $0,263 \mathrm{~m}$, respectively. It should be noted, that the amplitudes are not the same when the phenomenon of conductor galloping occurs. The movement of the conductor from the static balance to the upper position is slightly higher compared to the lower position. This has been repeatedly confirmed by numerous observations of the galloping of conductors on existing power lines and on experimental installations. 


\section{Conclusions}

The proposed calculation formula for the critical wind speed allows for an analysis of the characteristics of the air line, stationary aerodynamic coefficients of ice deposition and damping decrement on the stability of icy split-phase conductors in the wind flow.

Based on this analysis, the following conclusions are drawn:

1. The value of the lower critical wind speed at which the excited galloping of the conductors is significantly affected by the frequency of the free transverse vibrations of the conductors of the split phase, the damping decrement, and the aerodynamic characteristics of the profile of the icy conductors;

2. The configuration of the split phase (the number of conductors in the phase) practically does not affect the critical wind speed;

3. The lower critical wind speed does not depend on the method of attaching the conductor to the support (rigid or having a certain degree of freedom), that is, the galloping of the icy conductors of the split phase in the anchor span and multi-span system is excited under the same conditions.

Along with the novelty presented in the work, another significant advantage of the study is the developed calculation formula of the critical speed which can be used as an engineering method for estimating the critical (threshold) wind speed, which will allow dividing the boundary of a stable galloping from an unstable one and thus make it possible to construct areas of occurrence of the galloping of conductors for a specific air line at the specified parameters, conductor grade, aerodynamic characteristics and the decrement of oscillation. The scientific and practical results of this research work can also be used for further studies of conductor galloping, for compiling zoning maps of the territories according to the frequency of occurrence of galloping, taking into account climatic and geographical features, and for developing measures for protecting overhead power lines from galloping.

\section{References}

1 J.L. Lilien, D.G. Havard. Galloping Data Base on single and bundle conductors. Prediction of Maximum Amplitudes. IEEE Trans. power delivery. 15(2), pp.670-674 (2000)

2 C.B. Gurung, H. Yamaguchi, T. Yukino. Identification of large amplitude wind-induced vibration of ice-accreted transmission lines based on field observed data. J.Engineering Structures, 24 pp. 179-188 (2002)

3 O. Chabart, J.L. Lilien. Galloping of electrical lines in wind tunnel facilities. J.Wind engineering and industrial aerodynamics 74-76, pp. 967-976 (1998)

4 P. V. Dyke, Andre Laneville. Galloping of a single conductor covered with a D-section on a high-voltage overhead test line. J. Wind engineering and industrial aerodynamics 96, pp.1141-1151(2008)

5 L. Zhou, B. Yan, L. Zhang, S. Zhou. Study on galloping behavior of iced eight bundle conductor transmission lines. J. Sound and vibration 362, pp.85-110(2016)

6 Y.N. Bocharov, V.V. Titkov, R. Abitaeva, A.B. Bekbaev, M.A. Djamambaev. Torsion vibrations of splitted conductor of overhead transmissions. St. Petersburg polytechnic university. Engineering sciences and technology, 23(1), pp.84-91(2017) 
7 Y. Zhitao, L. Zh., S. Eric, L. William E. Galloping of a single iced conductor based on curved-beam theory. J. Wind eng. ind. aerodyn. 123, pp.77-87, (2013)

8 Y. Zhitao, S. Eric, L. Zh., L. William E. Galloping of iced quad-conductors bundles based on curved beam theory. J. Sound and vibration 333, pp.1657-1670. (2014)

9 W.Y. Ma, Q.K. Liu, X.Q. Du, Y.Y. Wei. Effect of the Reynolds number on the aerodynamic forces and galloping instability of a cylinder with semi-elliptical cross sections. J. Wind eng. ind. aerodyn. 146, pp.71-80, (2015)

10 A. Joly, S. Etienne, D. Pelletier Galloping of square cylinders in cross-flow at low Reynolds numbers. J. Fluids and structures 28, pp.232-243, (2012)

11 P. Augustin. Fluttering of the "electrical line galloping" type for conductors of continuous mass,- Buletinul institutulul politehnic "Gheorghe Gheorghiu-dej" Bucuresti. TVomul. XXIX, 3, pp. 103-107, (1967)

12 V.I. Vanko, I.K. Marchevsky. Pitching conductors of PLW - Lyapunov instability. Energy. News of higher educational institutions and energy associations of the CIS. 6, pp. 14-23, (2014) [in Russian]

13 L.K. Marchevsky. Mathematical modeling of the flow around a profile and research of its stability in a stream according to Lyapunov / dissertation abstract for the degree of candidate of physical and mathematical sciences. //. - M.: N.E. Bauman MSTU, (2008), [in Russian]

14 V.Ya. Gorin, N.N. Davidson, E.A. Marasina. Methodology for determining the critical wind speed when galloping conductors of overhead power lines. - // Science.Pratsi DonNTU, seriya "Electrical Engineering and Energy", 7 (128) .- Donetsk: DVNZ DonNTU, pp. 52-57, (2009), [in Russian]

15 F.N. Shklyarchuk, A.N. Danilin. Nonlinear vibrations and galloping of conductors with icing. - Bulletin of TulSU. Technical science. Energy, electricity, electric drive. 11 (188), pp. 188-197, (2013), [in Russian]

16 V.A. Feldstein, S.V. Kolosov, S.V. Ryzhov. VL conductor gallope model and calculation of protective equipment. - M .: Pub.house IAC "Energy". pp. 145-156. (2010), [in Russian]

17 M.A. Dzhamanbaev, N. Tokenov Mathematical model of the dance of the split phase of overhead power lines (anchor span) / proceedings of the II - international scientific conference "High Technologies - the Key to Sustainable Development", /. - Almaty, KazNTU named after K.I. Satbaev. vol. II, p. 5. (2013), [in Russian]

18 N. Tokenov, M. Dzhamanbayev, A. Bekbayev, D. Eskendirova, O. Baimuratov. Mathematical Model for Calculating Aerodynamic Characteristics of Overhead Transmission Lines. - J. Applied Mechanics and Materials. 610, pp 52-59. (2014)

19 M.A. Dzhamanbaev, K.S. Chakeeva, J.E. Karataeva, Z.A. Dzhumabekova. The method of calculating critical wind speeds in determining the area of aerodynamic instability of the conductors of the split phase of a multi-span power line // J. Measuring equipment, 6, pp. 25-30. (2019), [in Russian]

20. Terziev A., Analysis of the terrain specifics and roughness factor on the wind shear over complex terrains, IOP Conference Series Materials Science and Engineering 595:012043, September 2019, DOI: $\underline{\text { 10.1088/1757-899X/595/1/012043 }}$ 